
$\$$ Research Square
Preprints are preliminary reports that have not undergone peer review.
They should not be considered conclusive, used to inform clinical practice, or referenced by the media as validated information.

\title{
Preparation and characterization of multifunctional sponge-gourd fibers (Luffa cylindrica)/ hydroxyapatite composites for removal of lead and methylene
} blue

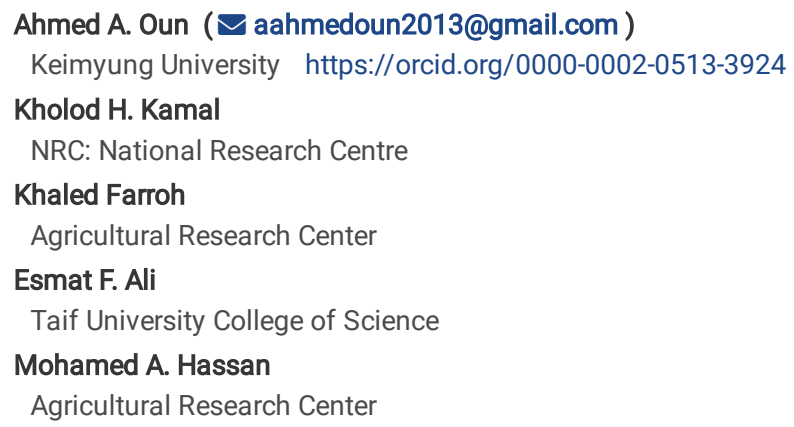




\section{Abstract}

Cellulose, oxidized-fibers, and oxidized-nanocellulose were isolated from sponge-gourd fibers (Luffa cylindrica). Isolated materials showed different morphology (shape and size), chemical, crystalline properties, and removal efficiency against methylene blue (MB) and lead ions ( $\left.\mathrm{Pb}^{2+}\right)$. The cellulosic materials showed high efficiency in removing $\mathrm{MB}$ more than $\mathrm{Pb}^{2+}$. So, different luffa forms/hydroxyapatite (HAp) composites were prepared and used as adsorbents for removal of both $\mathrm{MB}$ and $\mathrm{Pb}^{2+}$ from aqueous solutions. The effect of sorbent type, contact time, and initial $\mathrm{MB}^{2}$ and $\mathrm{Pb}^{2+}$ concentrations were studied. HAp was successfully synthesized on the surface of luffa with an average length of $40-56 \mathrm{~nm}$ and width of 14-19 nm. Kinetic and adsorption studies of $\mathrm{MB}$ and $\mathrm{Pb}^{2+}$ ions were well fitted with the pseudo-second-order model and Langmuir model. The maximum adsorption capacity of $\mathrm{MB}$ was 25.2 $\mathrm{mg} / \mathrm{g}, 30.8 \mathrm{mg} / \mathrm{g}$, and $36.2 \mathrm{mg} / \mathrm{g}$ for oxidized-fibers/HAp, oxidized-fibers, and cellulose, respectively, and for Pb ${ }^{2+}$ was $625 \mathrm{mg} / \mathrm{g}, 714 \mathrm{mg} / \mathrm{g}$, and $714.5 \mathrm{mg} / \mathrm{g}$ for oxidized-fibers/HAp, oxidized-nanocellulose/HAp, and cellulose/HAp, respectively. Also, more than $85 \%$ of MB (25 mg/L) and $95 \%$ of lead (500 mg/L) were removed within the first 5 min. Oxidize-fibers/HAp composite showed effective adsorption with both $\mathrm{MB}$ and $\mathrm{Pb}^{2+}$ in a very short time.

\section{Introduction}

The problem of water pollution is one of the biggest problems facing the world, especially in developing countries. It is very easy for water to become contaminated with highly toxic and hazardous organic dyes and heavy metals from different industrials wastes (Hokkanen et al. 2018). These pollutants can arrive at humans and other live organisms through contaminated food, water, and air, pose greater risks due to their high toxicity and serious accumulation problems. For obtaining usable water, several technologies such as precipitation, filtration, ion exchange, solvent extraction, coagulation, and adsorption have been used. While most of these technologies and used materials are very expensive products and require additional treatments (Tshikovhi et al. 2020).

For this, more attention has been given to biomaterials like cellulose-based materials, chitin, chitin-derivatives, gelatine, starch, etc., to remove contaminants from water. Among these biomaterials, cellulose is the most natural polymer plentiful, sustainable, environmentally friendly, and biocompatible on the earth (Li et al. 2015). Cellulose can be obtained from different raw materials such as wood, agricultural waste, agro-industrial residues, fruit and vegetable wastes, paper wastes, grasses, marine biomass, etc. (Kumar et al. 2020). The unique properties of cellulosic materials i.e. low-cost, high mechanical strength, and abundant functional hydroxyl groups make it a promising candidate in water treatment in the shape of membranes, adsorbents, absorbents, and flocculants (Mohammed et al. 2018).

Luffa sponge (Luffa cylindrica) is a tropical non-wood plant that has high cellulose content (55-90\%), used as a mold to produce porous materials, as reinforcement materials, in the pharmaceutical field, electrocatalysts, and water treatment (-Al-Mobarak et al. 2018; Mary Stella and Vijayalakshmi 2019). Recently, more attention has been given to luffa sponge fibers as effective adsorbents in the removal of heavy metals and dyes from contaminated water. It showed high efficiency as a natural bio-adsorbent in the removal of $\mathrm{Pb}^{2+}$ ions (Adewuyi and Pereira 2017a), methylene blue dye (Demir et al. 2008), Cu2+ and oil (Adewuyi and Pereira 2017b), and lanthanide (Liatsou et al. 2017) from contaminated water. However, it has frequently been observed that cellulosic materials have an effective ability in dyes removal, while low ability with heavy metals (Mallampati et al. 2015). For example, Adewuyi and Pereira (Adewuyi and Pereira 2017a) reported that the maximum adsorption capacity of Luffa cylindrica sponge to $\mathrm{Pb}^{2+}$ ions was $75.853 \mathrm{mg} / \mathrm{g}$. To overcome that problem, multifunctional materials have been prepared from two or more materials to take full advantage of composite materials.

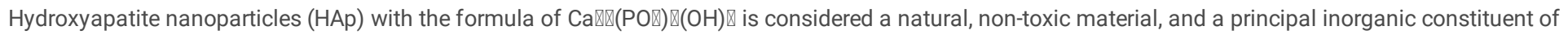
bones and teeth. So, It is extensively used in the biomedical field (Niamsap et al. 2019). In the water treatment field, HAp is one of the most effective removal materials of cationic and anionic contaminants from contaminated water. Using HAp as a composite with one or two materials increased the composite removal efficiency of a wide range of heavy metals (Hokkanen et al. 2018).

In this work, different luffa forms (oxidized-fibers, cellulose, and oxidized-nanocellulose) were isolated from luffa sponge-gourd fibers as a nonconventional cellulosic source, high cellulose content, low cost, and eco-friendly material. The effect of morphology, chemical structure of isolated materials, and presence or absence of HAp on the removal efficiency of methylene blue dye and $\mathrm{Pb}^{2+}$ ions was studied. Also, the study was conducted to determine the easiest and most effective way to obtain multifunction luffa/HAp composite with removal efficiency against both dyes and heavy metals, as illustrated in Fig. 1 .

\section{Materials And Methods}

\section{Materials}

Sponge-gourd fibers (Luffa cylindrica) were obtained from a local shop in Giza, Egypt. Calcium hydroxide $\left(\mathrm{Ca}(\mathrm{OH})_{2}\right)$, phosphoric acid $\left(\mathrm{H}_{3} \mathrm{PO} \mathrm{H}_{4}, 85 \%\right)$, acetic acid, and ammonium hydroxide (30\%) were purchased from (Sigma-Aldrich, St. Louis, MO, USA). Hydrogen peroxide $\left(\mathrm{H}_{2} \mathrm{O}_{2}, 30 \%\right)$ was obtained from (S.D fine Chem Limited Mumbai, India). Sodium Chlorite $\left(\mathrm{NaClO}_{2}\right)$ was supplied by (Carl Roth, $\mathrm{GmbH} \& \mathrm{Co}$. $\mathrm{Kg}$ ). Potassium hydroxide (KOH) was obtained from (Honeywell, GmbH, Germany).

\section{Isolation of cellulose from luffa fibers (LF)}

Cellulose was isolated from sponge-gourd fibers (Luffa cylindrica) following the method described by Oun and Rhim (Oun and Rhim 2016). Briefly, LF was cut into small pieces and washed several times with tap water to remove impurities and attached dust, then dried in an air oven at $100{ }^{\circ} \mathrm{C}$ for $24 \mathrm{~h}$. The dried LF was ground into fine powder for further use. Thirty grams of dried LF powder were dispersed into $1000 \mathrm{~mL}$ of sodium chlorite solution $1.4 \%$ (w/v) with adjusting the $\mathrm{pH}$ to 4 using $5 \%$ acetic acid and heated at $70{ }^{\circ} \mathrm{C} / 5 \mathrm{~h}$ with stirring to remove lignin. The mixture was washed with distilled water several times until the filtrate became neutral, then the residues were collected and oven-dried until constant of weight to calculate lignin content from the difference in 
weights. After removal of lignin, hemicellulose was removed by soaking of holocellulose (hemicellulose and a-cellulose) into $600 \mathrm{~mL}$ of $5 \% \mathrm{KOH}$ solution for $24 \mathrm{~h}$ at room temperature with stirring, then heated at $90{ }^{\circ} \mathrm{C} / 2 \mathrm{~h}$. Obtained cellulose was washed and dried to calculate the percentage of hemicellulose and cellulose. The resulted chemical composition of original Luffa fibers was cellulose $60 \%$, hemicelluloses $26.6 \%$, lignin $13.4 \%$ (Hong et al. 2020 ).

\section{Preparation of oxidized-fibers and oxidized-nanocellulose.}

Ground luffa fibers or isolated cellulose were used for isolation of oxidized-fibers and oxidized-nanocellulose, respectively. For this, $5 \mathrm{~g}$ of raw luffa fibers or isolated cellulose, separately were added into $100 \mathrm{~mL}$ of hydrogen peroxide (30\%) then heated at $90^{\circ} \mathrm{C}$ for $5 \mathrm{~h}$ with stirring. The suspensions were washed with distilled water several times to $\mathrm{pH} \sigma 6$ and dried in an air oven at $100^{\circ} \mathrm{C}$ until constant weight. The yields of the isolated oxidized-fiber and oxidizedcellulose were $54 \%$ and $50 \%$, respectively.

\section{Synthesis of luffa/hydroxyapatite composite}

Hydroxyapatite (HAp) was synthesized in the presence of different luffa forms following the method reported by Niamsap, Lam, and Sukyai (Niamsap et al. 2019) with modification. One gram of each luffa form (i.e. oxidized-fibers, cellulose, or oxidized nanocellulose) was redispersed into $100 \mathrm{~mL}$ of distilled water using a homogenizer (Stuart, SHM2 /EURO, USA) at $5000 \mathrm{rpm}$ until completely dispersed. Then, $0.741 \mathrm{~g}$ of calcium hydroxide was added to the previous suspension and sonicated in water bath sonication at $60^{\circ} \mathrm{C} / 30 \mathrm{~min}$. The pH of the suspension was adjusted to 10 using acetic acid and stirred for $60 \mathrm{~min} /$ $60{ }^{\circ} \mathrm{C}$. Phosphoric acid $(0.410 \mathrm{~mL}$ into $100 \mathrm{~mL}$ water) was added dropwise into the mixture and adjust the pH to 10 by ammonium hydroxide, with stirring at 60 ${ }^{\circ} \mathrm{C} / 3 \mathrm{~h}$. Finally, the mixture was aged at room temperature for $24 \mathrm{~h}$, then washed until pH 7-8, and dried at $80{ }^{\circ} \mathrm{C}$. Obtained powders were called oxidizedfiber/HAp, cellulose/HAp, and oxidized-nanocellulose/HAp.

\section{Characterization of luffa and luffa/hydroxyapatite sorbents}

Morphology and dimensions of oxidized-fibers and isolated cellulose were observed using field emission scanning electron microscopy (Quattor S, Thermo Scientific, USA). While, high-resolution transmission electron microscopy (HR-TEM, Tecnai G20, FEl, Netherland) was used for oxidized-nanocellulose, oxidizedfibers/hydroxyapatite, cellulose/hydroxyapatite, and oxidized-nanocellulose/hydroxyapatite imaging.

Fourier-transform infrared spectroscopy (FTIR- 6100 Jasco, Japan) was used to test the change in the chemical structure of sorbents, over a range of $4000-$ $400 \mathrm{~cm}^{-1}$ at room temperature.

X-ray diffraction (XRD) of sorbents was performed using XRD diffractometer (XRD -X'Pert PRO PANalytical, Netherland), which operated at $45 \mathrm{kV}$ and $30 \mathrm{~mA}$ using X-ray source "Cu Ka radiation" $(\lambda=1.5404 \AA)$ and high score plus software for peaks matching and analysis. Dry samples were scanned in the range of $2 \theta=10-80^{\circ}$ with a scanning rate of $0.4^{\circ} / \mathrm{min}$ at room temperature. The crystallinity index $(\mathrm{Cl})$ of samples was calculated using the following equation after subtraction of the background (Eq.1) (Park et al. 2010).

$$
\mathrm{CI}(\%)=\frac{\mathrm{I}_{200}-\mathrm{I}_{a m}}{\mathrm{I}_{200}} \times 100
$$

where $\mathrm{I}_{200}$ is the maximum intensity value for the crystalline cellulose at plane (200 and $\mathrm{I}_{\mathrm{am}}$ is the minimum intensity value for the amorphous cellulose (French 2014).

\section{Adsorption Studies}

\section{Effect of sorbents type}

A comparative adsorption study was carried out to determine the best efficient sorbent between the following samples, oxidized-fibers (S1), cellulose (S2), oxidized-nanocellulose (S3), oxidized-fibers/HAp (S4), cellulose/HAp (S5), and oxidized-nanocellulose/HAp (S6). Two representative contaminants, methyl blue (MB) and lead $\left(\mathrm{Pb}^{+2}\right)$ were used in this study. Precisely, a $0.4 \mathrm{~g}$ of the prepared sorbents was added to $100 \mathrm{~mL}$ of $25 \mathrm{mg} / \mathrm{L} \mathrm{methylene} \mathrm{blue} \mathrm{or} 100 \mathrm{mg} / \mathrm{L}$ lead ions solution separately. The mixtures were shaken for 120 minutes and filtered. Then, the remaining concentrations of MB were measured by spectrophotometer (Cary 5000, Varian, England) at wavelength $633 \mathrm{~nm}$, while the remaining $\mathrm{Pb}^{+2}$ ions concentrations were determined by the atomic absorption spectrometer (Varian SpectrAA220). The removal efficiency (R\%) of sorbents was calculated using the following equation (Eq.2):

$$
R \%=\left(C_{o}-\frac{C_{t}}{C_{o}}\right) X 100
$$

Where; $C_{o}$ and $C_{t}$ are the initial concentration and the remaining concentration of pollutants in $(\mathrm{mg} / \mathrm{L})$ after contact time $(t)$, respectively.

\subsubsection{Effect of contact time}

The batch experiments have been employed to study the influence of contact time on the removal efficiency of sorbents for $\mathrm{MB}(25 \mathrm{mg} / \mathrm{L})$ and $\mathrm{Pb}{ }^{+2}$ ions $(500$ $\mathrm{mg} / \mathrm{L}$ ). For this, $0.4 \mathrm{~g} / 100 \mathrm{~mL}$ of the best efficient sorbents (according to primary experiments results) were added to the contaminant solutions and the 
mixtures were shaken at room temperature for a certain time (2-120 min). The regular procedure of filtration and analysis was applied to calculate the removal efficiency (R\%) from equation (2).

\section{Effect of initial $\mathrm{MB}$ and $\mathrm{Pb}^{2+}$ ions concentrations}

The removal study at different concentrations of $\mathrm{MB}(5,10,25,50,100$ and $250 \mathrm{mg} / \mathrm{L})$ and $\mathrm{Pb}^{2+}$ ions $(200,500,1000,2000,3000$, and $4000 \mathrm{mg} / \mathrm{L})$ were also investigated at conditions of $0.4 \mathrm{~g} / 100 \mathrm{~mL}$ of the best efficient sorbents for contact time (120 min). To calculate the removal efficiency (R\%), the solutions were filtered and the remaining concentrations were measured.

\section{Kinetic and Isotherm Studies}

Four different kinetic models namely; pseudo-first-order (Sharma and Nandi 2013), pseudo-second-order (Azizian 2004), intra-particle diffusion (Doğan et al. 2004), and Elovich (Bharathi and Ramesh 2013) were used to identify the sorption rate constants of MB and $\mathrm{Pb}^{2+}$ ions removal. Furthermore, Langmuir (Gupta and Babu 2009), Freundlich, Temkin (Kumar et al. 2014), and The Dubinin-Radushkevich (D-R) (Dubinin 1947) adsorption isotherms were applied to study how the adsorbate molecules interact with the sorbent particles, as shown in Table (1). The equations and constants of the kinetic models and sorption isotherms were listed clearly in Table (1).

Table 1 Kinetics and isotherms models for the removal of pollutants onto sorbents

\begin{tabular}{|c|c|c|c|c|}
\hline \multicolumn{5}{|c|}{ Kinetics Models } \\
\hline 3ls & Equations & Variables & Graph & Remarks \\
\hline \multirow[t]{5}{*}{ o-first-order } & & $q_{e}:$ equilibrium sorption capacity $(\mathrm{mg} / \mathrm{g})$ & $\log \left(q_{e^{-}} q_{t}\right) \mathrm{Vs}$ & \\
\hline & $\log \left(q_{e^{-}} q_{t}\right)=\log q_{e^{-}}$ & $q_{t:}$ capacity of sorption $(\mathrm{mg} / \mathrm{g})$ at a time $(t, \mathrm{~min})$ & $t$ & ----- \\
\hline & $\left(k_{1} / 2.303\right) t$ & $k_{1}$ : the rate constant $\left(\mathrm{min}^{-1}\right)$ & & \\
\hline & Where; & $V:$ volume of solution (L) & & \\
\hline & $q_{t}=\left(C_{0}-C_{t}\right) *(V / M)$ & $M$ : mass of the sorbent added ( $\mathrm{g}$ ) & & \\
\hline o-second-order & $t / q_{t}=1 / k_{2} q_{e}+\left(1 / q_{e}\right) t$ & $k_{2:}$ the rate constant (g/mg. min) & $t / q_{t}$ Vs $t$ & ----- \\
\hline particle diffusion & $q_{t}=k_{p}(t)^{0.5}+c$ & $\begin{array}{l}k_{p}: \text { intra-particle diffusion rate }\left(\mathrm{mg} \cdot \mathrm{g}^{-1} \mathrm{~min}^{1 / 2}\right) \\
C: \text { constant }\end{array}$ & $q_{t}$ Vs $t^{0.5}$ & $\cdots$ \\
\hline h & $q_{t}=(1 / \beta) \ln (\alpha \beta)+(1 / \beta) \ln (t)$ & $\begin{array}{l}\beta: \text { the desorption constant }\left(\mathrm{mg} \cdot \mathrm{g}^{-1} \cdot \mathrm{min}\right) \\
\alpha: \text { the initial adsorption rate }\left(\mathrm{mg} \cdot \mathrm{g}^{-1} \cdot \mathrm{min}^{-1}\right)\end{array}$ & $q_{t} \mathrm{Vs} \ln t$ & ---- \\
\hline \multicolumn{5}{|c|}{ Isotherms Models } \\
\hline auir isotherm & $\begin{array}{l}C_{e} / q_{e}=1 / b q_{\max }+\left(1 / q_{\max }\right) C_{e} \\
R_{L}=1 /\left(1+b C_{0}\right)\end{array}$ & $\begin{array}{r}\text { the Langmuir constant }(\mathrm{l} / \mathrm{mg}): b \\
\text { : the maximum sorption capacity }(\mathrm{mg} / \mathrm{g}) q_{\max } \\
: \text { separation factor } R_{L}\end{array}$ & $C_{e} / q_{e}$ Vs $C_{e}$ & $\begin{array}{r}=1 \text { : shows linear adsorption } R_{L} \\
=0: \text { illustrates irreversible } R_{L} \\
>1 \text { : represents unfavorable } R_{L} \\
\text { adsorption } \\
0<R_{L}<1 \text { : indicated good adsorption }\end{array}$ \\
\hline dlich isotherm & $\ln q_{e}=\ln k_{f}+(1 / n) \ln C_{e}$ & $\begin{array}{l}k_{f}: \text { the Freundlich constant } \\
n: \text { the strength of adsorption }\end{array}$ & $\ln q_{e} \mathrm{Vs} \ln C_{e}$ & $\begin{array}{l}n=1: \text { characterizes linear adsorption } \\
n<1: \text { represents the chemical process } \\
n>1: \text { designates the physical process }\end{array}$ \\
\hline $\mathrm{n}$ isotherm & $q_{e}=(R T / b) \ln k_{t}+(R T / b) \ln C_{e}$ & $\begin{array}{l}b \text { : the Temkin constant corresponding to the adsorption } \\
\text { heat } \\
R \text { : the universal gas constant }(0.00813 \mathrm{~kJ} / \mathrm{mol} \mathrm{K}) \\
K_{t} \text { : the equilibrium binding constant }(\mathrm{mol} / \mathrm{l}) \\
T \text { : the temperature }(\mathrm{K})\end{array}$ & $q_{e} \mathrm{Vs} \ln C_{e}$ & ----- \\
\hline isotherm & $\begin{array}{l}\ln q_{e}=\ln q_{m}-\beta \mathbb{I}^{2} \\
\square=R T \ln \left(1+1 / C_{e}\right) \\
E=1 /(2 \beta)^{0.5}\end{array}$ & $\begin{array}{r}: \text { the activity coefficient } \beta \\
\quad \text { the Polanyi potential } \triangle \\
\quad \text { Sorption energy } E\end{array}$ & Vs $I^{2} \ln q_{e}$ & ------ \\
\hline
\end{tabular}

\section{Results And Discussion}

\section{Characterization studies}

\section{Morphology properties}

Morphology properties of different luffa samples with or without hydroxyapatite nanoparticles (HAp) are shown in Fig. 2. The structure of oxidized luffa fibers (S1) and isolated cellulose (S2) was observed using the field emission scanning electron microscope (FE-SEM) Fig. 2 (S1 and S2). The S1 and S2 samples showed long fibrils with rough surfaces, indicating that the oxidation process and chemical treatment have affected the structure of original Luffa fibers, which mainly was due to the removal of wax, non-cellulosic materials, and other extractives (Taimur-Al-Mobarak et al. 2018). The average width of S1 and $\mathrm{S} 2$ was $11.4 \pm 3.1 \mu \mathrm{m}$ and $13.3 \pm 1.0 \mu \mathrm{m}$, respectively.

The microstructure and dimensions of oxidized-nanocellulose (S3), oxidized-fibers/hydroxyapatite (S4), cellulose/HAp (S5), and oxidized-nanocellulose/HAp (S6) are determined using TEM imaging, as shown in Fig. 2 (S3-S6). The $\mathrm{S} 3$ sample was obtained via oxidation of isolated cellulose by $\mathrm{H}_{2} \mathrm{O}_{2}$, resulting in a needle-shaped structure with an average length of $192 \pm 37 \mathrm{~nm}$ and a width of $25 \pm 6 \mathrm{~nm}$. On the other hand, the resulted luffa forms were used as a carrier for loading HAp. It can be seen that HAp nanoparticles were successfully synthesized on the surface of samples, as shown in Fig. 2 (S4-S6). The average length 
and width of HAp synthesized on the surface of S4 were (56 $\pm 17 \mathrm{~nm}$ and $19 \pm 4 \mathrm{~nm}), \mathrm{S} 5$ (53 $\pm 14 \mathrm{~nm}$ and $22 \pm 5 \mathrm{~nm}$ ), and S6 (40 $\pm 19 \mathrm{~nm}$ and $14 \pm 3 \mathrm{~nm}$ ). It is interesting to note that HAp nanoparticles are presented in abundance but relatively agglomerated on the surface of the S4 sample. However, it is densely and uniformly attached to the surface cellulose (S5). While in the case of sample S6 sample, it showed less content of HAp, which probably was related to the small dimensions of prepared oxidized-nanocellulose. Also, it looks that the presence of HAp helped in an agglomeration of the oxidized-nanocellulose (S6) as compared to without HAp (S3). Similar agglomeration behavior was observed when different ratios of HAp prepared with nanocellulose (Lu et al. 2019). It can be concluded that the size of luffa samples played a significant role in synthesizing and attaching HAp on their surfaces.

\section{FTIR analysis}

Change in the chemical structure of luffa samples with or without HAp was performed via FTIR analysis and the results are shown in Fig. 3. The characteristic absorption peaks of oxidized-Luffa fibers (S1), cellulose (S2), and oxidized nanocellulose (S3) are observed at $3334 \mathrm{~cm}^{-1}(\mathrm{O}-\mathrm{H}$ stretching vibrations), 2898 $\mathrm{cm}^{-1}$ ( $\mathrm{CH}_{2}$ groups of cellulose), $1631 \mathrm{~cm}^{-1}$ (O-H vibration), $1429 \mathrm{~cm}^{-1}$ (O-H vibration), $897 \mathrm{~cm}^{-1}$ ( $\beta$-glycosidic linkages between glucose units) (Niamsap et al. 2019). The FTIR spectra of Luffa fibers (S1) and oxidized-nanocellulose (S3) samples exhibited a new absorption peak at $1733 \mathrm{~cm}^{-1}$, resulted from the introduction of $\mathrm{C}=\mathrm{O}$ group after $\mathrm{H}_{2} \mathrm{O}_{2}$ treatment (Oun and Rhim 2018).

The characteristic peaks of HAp which loaded on the surface of Luffa samples were detected at $1026 \mathrm{~cm}^{-1} \mathrm{due}$ to $\mathrm{PO}_{4}{ }^{3-} \mathrm{group}$ stretching mode ( $\otimes 3$, $\otimes 1$ ) and at $871 \mathrm{~cm}^{-1}$ correspond to $\otimes 1 \mathrm{CO}_{3}{ }^{2-}$ (Yu et al. 2013). It can be seen that the peak intensity of O-H and C-H groups were decreased as shown in Fig. 3 (S4, S5, and S6), probably due to the interaction of these groups with HAp, which helped in attaching HAp on the surface of CNCs (Narwade et al. 2017).

\section{$X R D$ analysis}

The XRD analysis was used to determine of crystalline structure and chemical composition of Luffa samples with and without HAp. The XRD diffraction patterns of luffa and luffa/HAp samples are shown in Fig. 4. The characteristic peaks of cellulose were observed at lattice planes (110), (200), and (004), which is related to native cellulose structure (Oun and Rhim 2016). oxidized-luffa fibers (S1), isolated cellulose (S2), and oxidized- nanocellulose (S3) showed different diffraction pattern intensities due to chemical treatments. Treatment of luffa fibers with $\mathrm{H}_{2} \mathrm{O}_{2}$ presented less peak intensities, compared to sample S2 and $\mathrm{S} 3$, which probably due to the role of $\mathrm{H}_{2} \mathrm{O}_{2}$ in removal of lignin only. While in the case of sample $\mathrm{S} 2$, the peak intensity was increased which, maybe due to the removal of non-cellulosic parts (hemicellulose and lignin). Compared to sampleS1 and S2, sample S3 presented the highest peak intensity, and this perhaps due to not only removal of non-cellulosic parts but also amorphous regions in cellulose fibers (Oun and Rhim 2018). The crystallinity index (Cl) was calculated using Eq. (1) and the results were $73.5 \%, 82.4 \%$, and $84.4 \%$ for samples S1, S2, and S3, respectively.

After loading of HAp on the surface of luffa samples, the intensity of cellulose peaks was significantly diminished, as shown in Fig. 4 (S4-S6). The Cl of composite samples was decreased to $70.2 \%, 66.6 \%$, and $55.9 \%$ for S4, S5, and S6, respectively, as compared to samples without $\mathrm{HAp}$. The reduction in the $\mathrm{Cl}$ of composite samples was probably due to covering of characteristic cellulose peaks by HAp. Similar results were observed when metallic nanoparticles such as AgNPs, CuONPs, and ZnONPs formed on the surface of regenerated cellulose (Shankar et al. 2018).

The inset figure (Fig. 4) shows of XRD analysis of luffa/ HAp composite samples. It worth noting that new peaks have been observed in Luffa/HAp composites at $2 \theta=26.9^{\circ}, 32.9^{\circ}, 40.7^{\circ}, 47.6^{\circ}, 49.6^{\circ}, 53.2^{\circ}$, and $63.9^{\circ}$ (Narwade et al. 2017). These new peaks indicate to formation of HAp onto the surface of different forms of luffa samples with different peak intensities (Niamsap et al. 2019).

\section{Adsorption studies}

\section{Effect of sorbent type}

Converting of cellulosic materials into nanocellulose forms e.g. cellulose nanofibrils (CNFs) and cellulose nanocrystals (CNCs), led to an increase in their surface area, lightweight, and the ability to add different functional groups that improve their adsorption capacities of heavy metal ion and dye (Tshikovhi et al. 2020).

Fig. 5, shows a comparative study of $0.4 \mathrm{~g}$ of the prepared sorbents for removing methylene blue (MB) and lead ions $\left(\mathrm{Pb}^{2+}\right)$ from $100 \mathrm{~mL}$ aqueous solutions after 120 minutes. The data showed that the removal efficiency of MB by S1, S2, and S4 sorbents is higher than the other sorbents, which reached $85 \%$, $89.6 \%$, and $83.8 \%$ respectively (Fig. 5A). The obvious increase in the removal efficiency of MB by these sorbents over the other sorbents probably was due to the presence of abundant functional hydroxyl and carboxyl groups on the surface of nanocellulose that facilitate the interaction of chemical moieties. Also, the web-shape structure of long fibrils may be played an important role as a net and trapped the dye molecules (Li, Ma, Venkateswaran, \& Hsiao, 2020). Previously, different cellulose materials have been used for removal of dyes from contaminated water. The removal efficiency of materials has been affected by the source, size, and surface modifications of used cellulose, as well as types of loaded materials (Varghese et al. 2019).

The data also showed that samples S4, S5, and S6 have the highest removal efficiency for lead ions over other sorbent materials, which reached $96.9 \%$, $97.8 \%$, and $96.3 \%$, respectively (Fig. 5B). The higher removal \% of these sorbents can be attributed to the presence of hydroxyapatite nanoparticles which have a great affinity to adsorb the heavy metal ions (Bailliez et al. 2004).

\section{Effect of contact time}

Fig. 6, display the effect of contact time on the removal efficiency of sorbents for methylene blue (Fig. 6A) and lead ions (Fig. 6B). According to primary experiments, samples S1 (oxidized-fibers), S2 (cellulose of luffa), and S4 (oxidized-fibers/HAp) showed the best efficient sorbents in removal of MB as shown 
in Fig. 5A. While samples S4 (oxidized-luffa fibers/HAp), S5 (cellulose/ HAp), and S6 (oxidized-nanocellulose/HAp) were the best in removal of Pb²+ ions (Fig. $5 B)$. For this, these samples have been chosen to test the effect of contact time on their removal efficiency.

It can be seen that a quick removal within the first 5 min of the adsorption process was obtained with the removal rate of more than $85 \%$ for $\mathrm{MB}$ and more than $95 \%$ for $\mathrm{Pb}^{2+}$ ions. Then, a slower sorption step continued until reaching a state of equilibrium. This behavior possibly is due to the availability of sufficient active sites at the beginning of the reaction, after that the active sites became occupied by MB and Lead ions (Abd El-Aziz et al. 2018).

On the other side, the kinetic studies and rate constants of $\mathrm{MB}$ and $\mathrm{Pb}^{2+}$ ions sorption by sorbents were elucidated after applying the pseudo-first-order, pseudo-second-order, intra-particle diffusion model, and Elovich model. The kinetic model's constants and correlation coefficients of $\mathrm{MB}$ and $\mathrm{Pb}{ }^{2+}$ ions were calculated and presented in Table (2) and (3), respectively. Interestingly from the data, the kinetics of sorption reaction was perfectly fitted to the pseudosecond-order model for both methylene blue (Fig. 6C) and lead ions (Fig. 6D) which assumes that the rate of solute adsorption is directly proportional to the square of the number of vacant binding sites (Choudhary and Paul 2018). This may be attributed to the higher correlation coefficient value $\left(R^{2}\right)$, and the close matching between the experimental and calculated sorption capacities from this model (Kamal et al. 2019).

\section{Effect of the initial $\mathrm{MB}$ and $\mathrm{Pb}^{2+}$ ions concentrations}

The initial concentration of contaminants is one of the most important factors in adsorption efficiency. Consequently, the removal efficiency was tested using $0.4 \mathrm{~g}$ of the selected sorbents at different $\mathrm{MB}$ and $\mathrm{Pb}^{2+}$ ion concentrations (Fig. 7A and 7). The data presented in Fig. 7A shows that with the increase in the initial concentration of MB from 5 to $225 \mathrm{mg} / \mathrm{L}$, the sorption efficiency decreased gradually from $100 \%$ to 51,59 , and $40 \%$ for S1, S2, and S4, respectively. This behavior can be attributed to the saturation of the most active sites of the sorbents by MB molecules (Aksu and Tezer 2005). While Fig. 7B shows a steady sorption efficiency of around $100 \%$ at a concentration range of $\mathrm{Pb}^{2+}$ ions (200-1000 mg/L) for samples S4, S5, and S6. After increasing the $\mathrm{Pb}$ concentration from $1000 \mathrm{mg} / \mathrm{L}$ to $4000 \mathrm{mg} / \mathrm{L}$, it was found that the sorption efficiencies gradually decreased to achieve 63,75 , and 70\% for S4, S5, and S6, respectively. This higher ability of sorbents to adsorb more $\mathrm{Pb} 2+$ compared to $\mathrm{MB}$ is attributed to the small size of lead ions (ionic radius of $\mathrm{Pb}^{2+}$ ions (1.33 $\AA$ ) rather than the large dye molecules (estimated area of MB molecule (130-135 $\mathrm{A})$ ) which allows less adsorption competition on the available sorbent sites (Aljeboree et al. 2017).

On the other hand, to illustrate how the $\mathrm{MB}$ and $\mathrm{Pb}^{2+}$ ions interact with the sorbents; Langmuir, Freundlich, Temkin, and Dubinin-Radushkevich ( $\mathrm{D}-\mathrm{R}$ ) isotherm models were studied. The constants and correlation coefficients calculated from the isotherm models were listed in Table 2 and Table 3 . Remarkably from the data and correlation coefficients, See Fig. 7 ( $C$ and $D$ ), the sorption of $\mathrm{MB}$ and $\mathrm{Pb}^{2+}$ ions were fitted with the Langmuir model which assumes monolayer adsorption of the $\mathrm{MB}$ and $\mathrm{Pb}^{2+}$ ions onto active sites of the sorbent's surface (Gupta and Babu 2009). The value of $\mathrm{n}>1$ in Freundlich and $\mathrm{E}<8$ in (D-R) model demonstrating that the adsorption is a physical process (Kumar et al., 2014). Moreover, the separation factor (RL) values were found to be in the range from 0 to 1 , which proposing favorable adsorption between sorbents and sorbates.

The maximum $\mathrm{MB}$ and $\mathrm{Pb}^{2+}$ ions sorption capacities $\left(\mathrm{q}_{\max }\right)$ of the selected sorbents which calculated from the Langmuir model were compared with different sorbents in previous studies as presented in Table (4). The data indicated that the prepared sorbents have a good ability to remove $\mathrm{MB}$ and $\mathrm{Pb}{ }^{2+}$ ions from the solution.

Table 2 Constants of kinetic models and isotherm models for MB removal.

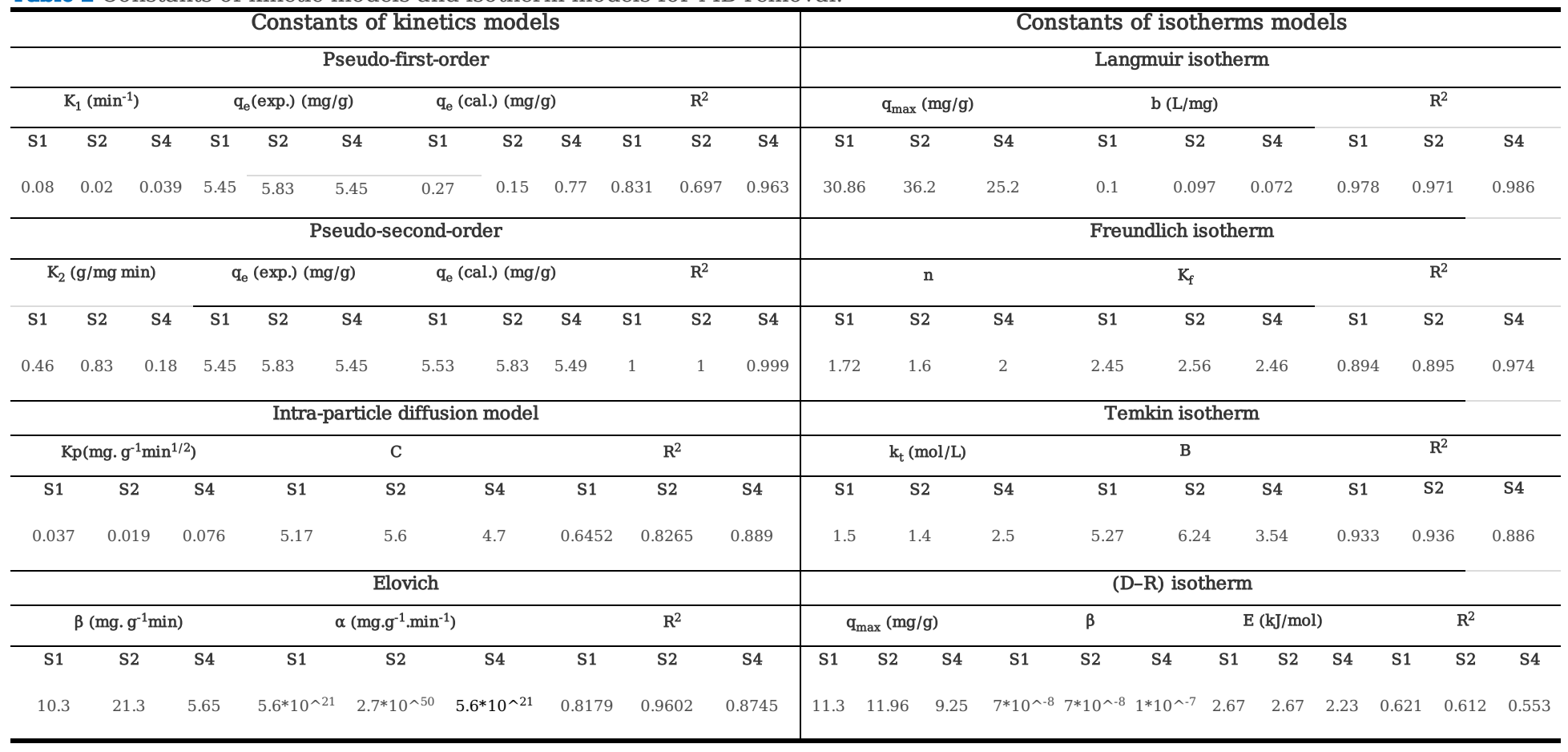


Table 3 Constants of kinetic models and isotherm models for $\mathrm{Pb}^{2+}$ ions removal.

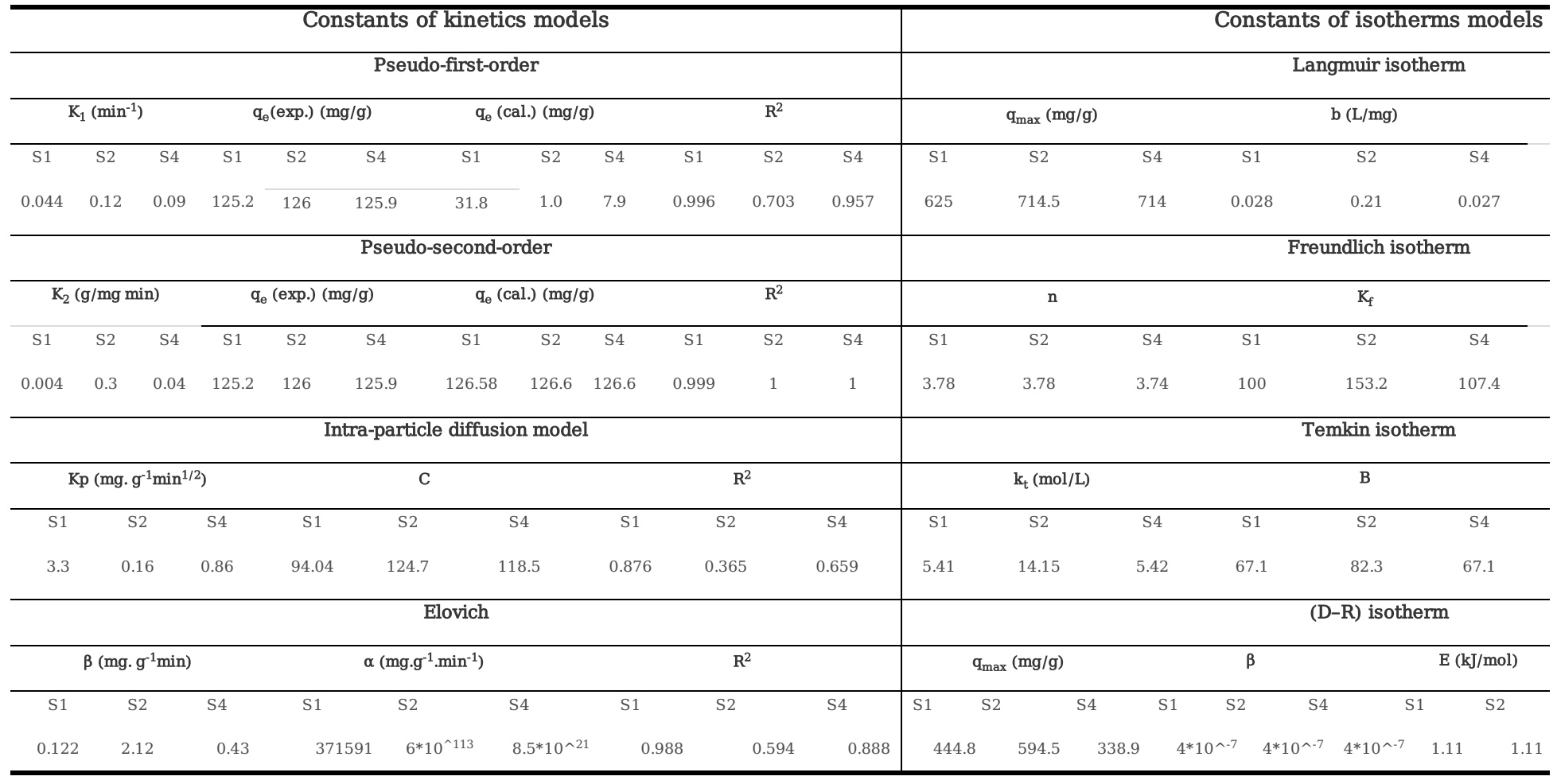

Table 4 Comparison of adsorption capacity of methylene blue and lead ions with several sorbents reported in the literature

\begin{tabular}{|c|c|c|c|c|c|}
\hline \multicolumn{3}{|c|}{ Methylene blue } & \multicolumn{3}{|c|}{ Lead ions $\left(\mathrm{Pb}^{2+}\right)$} \\
\hline Sorbent & $\begin{array}{c}\text { Adsorption } \\
\text { Capacity, (mg/g) }\end{array}$ & References & Sorbent & $\begin{array}{c}\text { Adsorption } \\
\text { Capacity, (mg/g) }\end{array}$ & References \\
\hline $\begin{array}{l}\text { Neem (Azadirachta } \\
\text { indica) leaf powder }\end{array}$ & 8.7 & $\begin{array}{c}\text { (Bhattacharya and } \\
\text { Sharma 2005) }\end{array}$ & $\begin{array}{l}\text { Cellulose-MT-CBM } \\
\text { biosorbents }\end{array}$ & 39.0 & $\begin{array}{c}\text { (Mwandira et al. } \\
\text { 2020) }\end{array}$ \\
\hline Freeze-dried agarose gel & 10.4 & $\begin{array}{c}\text { (Seow and Hauser } \\
\text { 2016) }\end{array}$ & Cellulose & 43.9 & $\begin{array}{l}\text { (Aquino et al. } \\
\text { 2018) }\end{array}$ \\
\hline $\begin{array}{l}\mathrm{H} 2 \mathrm{SO} 4 \text { cross-linked } \\
\text { magnetic chitosan }\end{array}$ & 20.4 & (Rahmi et al. 2019) & Natural clinoptilolite & 80.9 & $\begin{array}{c}\text { (Günay et al. } \\
\text { 2007) }\end{array}$ \\
\hline Carbon- $\mathrm{TiO}_{2}$ composite & 25.7 & (Simonetti et al. 2016) & Nanohydroxyapatite & 192.3 & $\begin{array}{l}\text { (Mohammad et } \\
\text { al. 2017) }\end{array}$ \\
\hline Oxidized-fibers (S1) & 30.8 & (Present work) & $\begin{array}{l}\text { Oxidized fibers/HAp } \\
\text { (S4) }\end{array}$ & 625.0 & (Present work) \\
\hline Cellulose (S2) & 36.2 & (Present work) & Cellulose/HAp (S5) & 714.5 & (Present work) \\
\hline Oxidized-fibers/HAp (S4) & 25.2 & (Present work) & $\begin{array}{l}\text { Oxidized } \\
\text { nanocellulose/HAp } \\
\text { (S6) }\end{array}$ & 714.50 & (Present work) \\
\hline
\end{tabular}

\section{Conclusion}

Three diverse luffa forms in shape, size, and chemical structure have been obtained via using different isolation strategies. The effect of luffa properties and the presence or absence of hydroxyapatite ( $\mathrm{HAp})$ on the removal efficiency of methylene blue (MB) and lead ions $\left(\mathrm{Pb}^{2+}\right)$ from aqueous solutions has been studied. The sorbents with long fibrils and web-like structures were very effective in removing MB compared to samples with short and needle-shaped structures. Also, luffa samples loaded with $\mathrm{HAp}$ were more effective in removing both $\mathrm{Pb}^{2+}$ and $\mathrm{MB}$ as compared to samples without $\mathrm{HAp}$. The maximum adsorption capacity was $25-36 \mathrm{mg} / \mathrm{g}$ for MB and $625-714.5 \mathrm{mg} / \mathrm{g}$ for lead ions, depending on sorbent type. Among all samples, oxidized-luffa fibers/HAp composite showed the most effective composite in the removal of both $\mathrm{MB}$ and $\mathrm{Pb}^{2+}$ ions. Also, the results showed that more than $85 \%$ of $\mathrm{MB}$ and $95 \%$ of lead ions were quickly removed within the first $5 \mathrm{~min}$ of the adsorption process.

\section{Declarations}


This work was supported by Nanotechnology and Advanced Materials Central Lab, Regional Center for Food \& Feed, Agricultural Research Center; and Taif University Researchers Supporting Project number (TURSP-2020/65), Taif University, Taif, Saudi Arabia for financial support and research facilities.

\section{Compliance with ethical standards}

Conflict of interest There are no conflicts of interests to declare.

\section{References}

1. -Al-Mobarak T, Gafur MA, Mina MF (2018) Preparation and Characterization of Raw and Chemically Modified Sponge-Gourd Fiber Reinforced Polylactic Acid Biocomposites. Mater Sci Appl 09:281-304. https://doi.org/10.4236/msa.2018.92019

2. Abd El-Aziz ME, Kamal KH, Ali KA et al (2018) Biodegradable grafting cellulose/clay composites for metal ions removal. Int J Biol Macromol 118:22562264. https://doi.org/10.1016/j.ijbiomac.2018.07.105

3. Adewuyi A, Pereira FV (2017a) Underutilized Luffa cylindrica sponge: A local bio-adsorbent for the removal of Pb(II) pollutant from water system. BeniSuef Univ J Basic Appl Sci 6:118-126. https://doi.org/10.1016/j.bjbas.2017.02.001

4. Adewuyi A, Pereira FV (2017b) Isolation and surface modification of cellulose from underutilized Luffa cylindrica sponge: A potential feed stock for local polymer industry in Africa. J Assoc Arab Univ Basic Appl Sci 24:39-45. https://doi.org/10.1016/j.jaubas.2016.12.003

5. Aksu Z, Tezer S (2005) Biosorption of reactive dyes on the green alga Chlorella vulgaris. Process Biochem 40:1347-1361. https://doi.org/10.1016/j.procbio.2004.06.007

6. Aljeboree AM, Alshirifi AN, Alkaim AF (2017) Kinetics and equilibrium study for the adsorption of textile dyes on coconut shell activated carbon. Arab J Chem 10:S3381-S3393. https://doi.org/10.1016/j.arabjc.2014.01.020

7. Aquino RR, Tolentino MS, Elacion RMPD et al (2018) Adsorptive removal of lead ( $\mathrm{Pb} 2+$ ) ion from water using cellulose acetate/polycaprolactone reinforced nanostructured membrane. IOP Conf Ser Earth Environ Sci 191:012139. https://doi.org/10.1088/1755-1315/191/1/012139

8. Azizian S (2004) Kinetic models of sorption: A theoretical analysis. J Colloid Interface Sci 276:47-52. https://doi.org/10.1016/j.jcis.2004.03.048

9. Bailliez S, Nzihou A, Bèche E, Flamant G (2004) Removal of lead (Pb) by hydroxyapatite sorbent. Process Saf Environ Prot 82:175-180. https://doi.org/10.1205/095758204322972816

10. Bharathi KS, Ramesh ST (2013) Removal of dyes using agricultural waste as low-cost adsorbents: a review. Appl Water Sci 3:773-790. https://doi.org/10.1007/s13201-013-0117-y

11. Bhattacharya KG, Sharma A (2005) Kinetics and thermodynamics of Methylene Blue adsorption on Neem (Azadirachta indica) leaf powder. Dye Pigment 65:51-59. https://doi.org/10.1016/j.dyepig.2004.06.016

12. Choudhary B, Paul D (2018) Isotherms, kinetics and thermodynamics of hexavalent chromium removal using biochar. J Environ Chem Eng 6:2335-2343. https://doi.org/10.1016/j.jece.2018.03.028

13. Demir H, Top A, Balköse D, Ülkü S (2008) Dye adsorption behavior of Luffa cylindrica fibers. J Hazard Mater 153:389-394. https://doi.org/10.1016/j.jhazmat.2007.08.070

14. Doğan M, Alkan M, Türkyilmaz A, Özdemir Y (2004) Kinetics and mechanism of removal of methylene blue by adsorption onto perlite. J Hazard Mater 109:141-148. https://doi.org/10.1016/j.jhazmat.2004.03.003

15. Dubinin MM (1947) The Equation of the Characteristic Curve of Activated Charcoal. Proc USSR Acad Sci 55:327-329

16. French AD (2014) Idealized powder diffraction patterns for cellulose polymorphs. Cellulose 21:885-896. https://doi.org/10.1007/s10570-013-0030-4

17. Günay A, Arslankaya E, Tosun I (2007) Lead removal from aqueous solution by natural and pretreated clinoptilolite: Adsorption equilibrium and kinetics. J Hazard Mater 146:362-371. https://doi.org/10.1016/j.jhazmat.2006.12.034

18. Gupta S, Babu BV (2009) Removal of toxic metal $\mathrm{Cr}(\mathrm{VI})$ from aqueous solutions using sawdust as adsorbent: Equilibrium, kinetics and regeneration studies. Chem Eng J 150:352-365. https://doi.org/10.1016/j.cej.2009.01.013

19. Hokkanen S, Bhatnagar A, Srivastava V et al (2018) Removal of Cd2+, Ni2 + and PO43 - from aqueous solution by hydroxyapatite-bentonite claynanocellulose composite. Int J Biol Macromol 118:903-912. https://doi.org/10.1016/j.ijbiomac.2018.06.095

20. Hong S, Song Y, Yuan Y et al (2020) Production and characterization of lignin containing nanocellulose from luffa through an acidic deep eutectic solvent treatment and systematic fractionation. Ind Crops Prod 143:111913. https://doi.org/10.1016/j.indcrop.2019.111913

21. Kamal KH, Attia MS, Ammar NS, Abou-Taleb EM (2019) Methylene blue removal from wastewater using silica/corncob nanocomposite Kholod. Int J Dev 8:81-93

22. Kumar PS, Palaniyappan M, Priyadharshini M et al (2014) Adsorption of Basic Dye onto Raw and Surface-modified Agricultural Waste. Environ Prog Sustain Energy 33:87-98.

23. Kumar V, Pathak P, Bhardwaj NK (2020) Waste paper: An underutilized but promising source for nanocellulose mining. Waste Manag 102:281-303. https://doi.org/10.1016/j.wasman.2019.10.041

24. Li C, Ma H, Venkateswaran S, Hsiao BS (2020) Highly efficient and sustainable carboxylated cellulose filters for removal of cationic dyes/heavy metals ions. Chem Eng J 389:123458. https://doi.org/10.1016/j.cej.2019.123458

25. Li MC, Wu Q, Song K et al (2015) Cellulose Nanoparticles: Structure-Morphology-Rheology Relationships. ACS Sustain Chem Eng 3:821-832. https://doi.org/10.1021/acssuschemeng.5b00144 
26. Liatsou I, Pashalidis I, Oezaslan M, Dosche C (2017) Surface characterization of oxidized biochar fibers derived from Luffa Cylindrica and lanthanide binding. J Environ Chem Eng 5:4069-4074

27. Lu J, Sun C, Yang K et al (2019) Properties of polylactic acid reinforced by hydroxyapatite modified nanocellulose. Polymers (Basel) 11:1-13. https://doi.org/10.3390/polym11061009

28. Mallampati R, Tan KS, Valiyaveettil S (2015) Utilization of corn fibers and luffa peels for extraction of pollutants from water. Int Biodeterior Biodegrad 103:8-15. https://doi.org/10.1016/j.ibiod.2015.03.027

29. Mary Stella S, Vijayalakshmi U (2019) Influence of chemically modified Luffa on the preparation of nanofiber and its biological evaluation for biomedical applications. J Biomed Mater Res - Part A 107:610-620. https://doi.org/10.1002/jbm.a.36577

30. Mohammad AM, Salah Eldin TA, Hassan MA, El-Anadouli BE (2017) Efficient treatment of lead-containing wastewater by hydroxyapatite/chitosan nanostructures. Arab J Chem 10:683-690. https://doi.org/10.1016/j.arabjc.2014.12.016

31. Mohammed N, Grishkewich N, Tam KC (2018) Cellulose nanomaterials: Promising sustainable nanomaterials for application in water/wastewater treatment processes. Environ Sci Nano 5:623-658. https://doi.org/10.1039/c7en01029j

32. Mwandira W, Nakashima K, Togo Y et al (2020) Cellulose-metallothionein biosorbent for removal of Pb(II) and Zn(II) from polluted water. Chemosphere 246:125733. https://doi.org/10.1016/j.chemosphere.2019.125733

33. Narwade VN, Khairnar RS, Kokol V (2017) In-situ synthesised hydroxyapatite-loaded films based on cellulose nanofibrils for phenol removal from wastewater. Cellulose 24:4911-4925. https://doi.org/10.1007/s10570-017-1435-2

34. Niamsap T, Lam NT, Sukyai P (2019) Production of hydroxyapatite-bacterial nanocellulose scaffold with assist of cellulose nanocrystals. Carbohydr Polym 205:159-166. https://doi.org/10.1016/j.carbpol.2018.10.034

35. Oun AA, Rhim JW (2016) Isolation of cellulose nanocrystals from grain straws and their use for the preparation of carboxymethyl cellulose-based nanocomposite films. Carbohydr Polym 150:187-200. https://doi.org/10.1016/j.carbpol.2016.05.020

36. Oun AA, Rhim JW (2018) Isolation of oxidized nanocellulose from rice straw using the ammonium persulfate method. Cellulose 25:2143-2149. https://doi.org/10.1007/s10570-018-1730-6

37. Park S, Baker JO, Himmel ME et al (2010) Cellulose crystallinity index: measurement techniques and their impact on interpreting cellulase performance. Biotechnol Biofuels 3:10-20

38. Rahmi I, Mustafa I (2019) Methylene blue removal from water using H2SO4 crosslinked magnetic chitosan nanocomposite beads. Microchem J 144:397-402. https://doi.org/10.1016/j.microc.2018.09.032

39. Seow WY, Hauser CAE (2016) Freeze-dried agarose gels: A cheap, simple and recyclable adsorbent for the purification of methylene blue from industrial wastewater. J Environ Chem Eng 4:1714-1721. https://doi.org/10.1016/j.jece.2016.02.013

40. Shankar S, Oun AA, Rhim J-W (2018) Preparation of antimicrobial hybrid nano-materials using regenerated cellulose and metallic nanoparticles. Int J Biol Macromol 107:17-27

41. Sharma N, Nandi BK (2013) Utilization of sugarcane baggase, an agricultural waste to remove malachite green dye from aqueous solutions. J Mater Environ Sci 4:1052-1065

42. Simonetti EAN, De Simone Cividanes L, Campos TMB et al (2016) Carbon and TiO2 synergistic effect on methylene blue adsorption. Mater Chem Phys 177:330-338. https://doi.org/10.1016/j.matchemphys.2016.04.035

43. Taimur-Al-Mobarak, Mina MF, Gafur MA et al (2018) Effect of Chemical Modifications on Surface Morphological, Structural, Mechanical, and Thermal Properties of Sponge-gourd Natural Fiber. Fibers Polym 19:31-40

44. Tshikovhi A, Mishra SB, Mishra AK (2020) Nanocellulose-based composites for the removal of contaminants from wastewater. Int J Biol Macromol 152:616-632. https://doi.org/10.1016/j.ijbiomac.2020.02.221

45. Varghese AG, Paul SA, Latha MS (2019) Remediation of heavy metals and dyes from wastewater using cellulose-based adsorbents. Environ Chem Lett 17:867-877

46. Yu X, Tong S, Ge M, Zuo J (2013) Removal of fluoride from drinking water by cellulose@hydroxyapatite nanocomposites. Carbohydr Polym 92:269-275. https://doi.org/10.1016/j.carbpol.2012.09.045

\section{Figures}



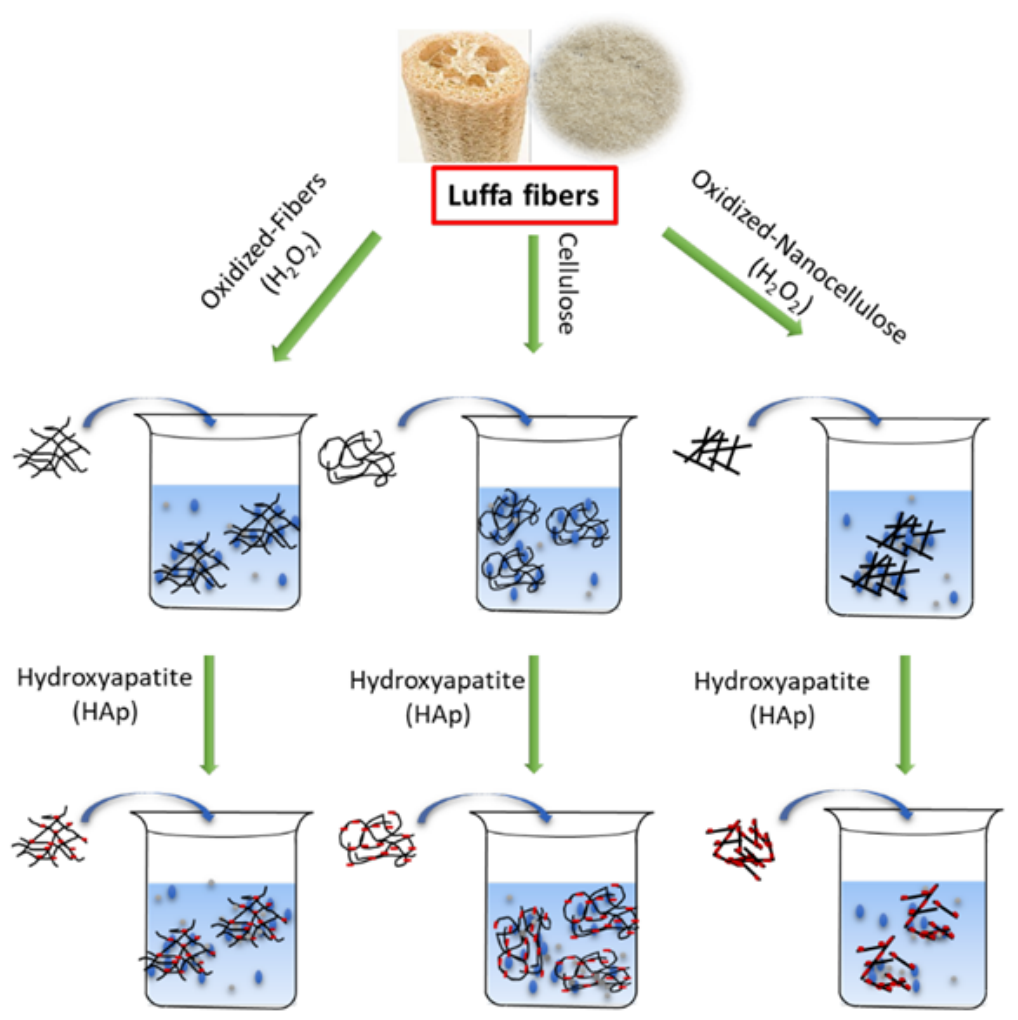

- Methylene blue $(\mathrm{MB}) \quad$ Lead ions $\left(\mathrm{Pb}^{2+}\right) \quad$ HAp

\section{Figure 1}

Schematic illustration for preparation of luffa/HAp composites for removal of methylene blue and lead ions
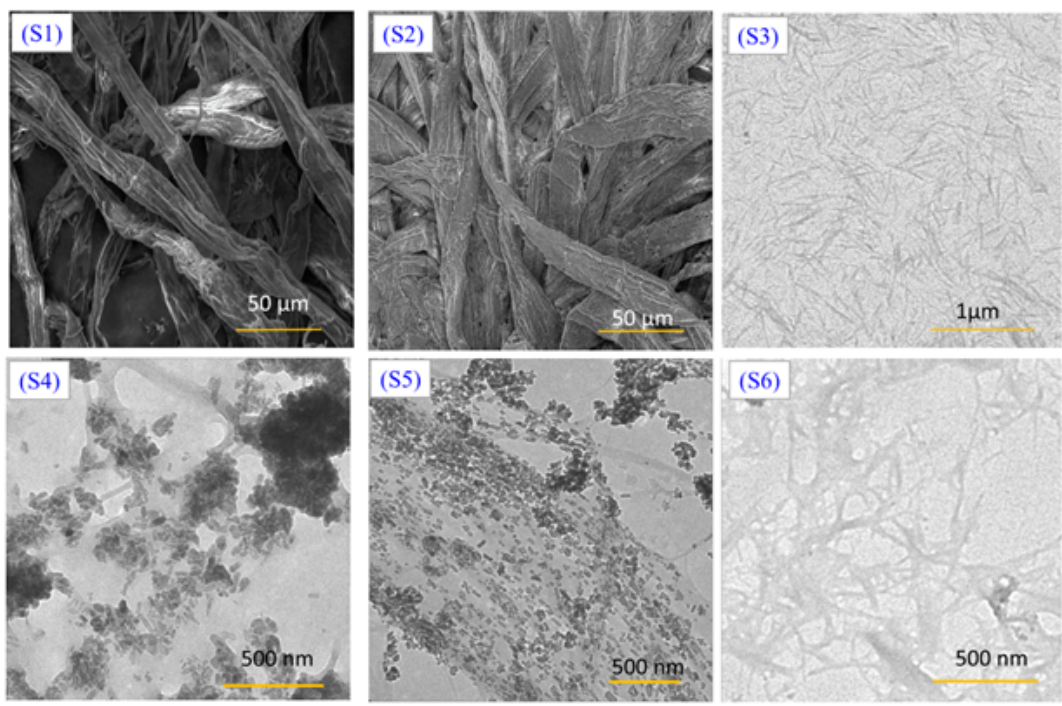

\section{Figure 2}

SEM images of (S1) Oxidized-Luffa fibers and (S2) Isolated Cellulose from Luffa; TEM images of (S3) Oxidized-nanocellulose, (S4) Oxidized-luffa fibers/HAp, (S5) Cellulose/HAp, and (S6) Oxidized-nanocellulose/HAp 


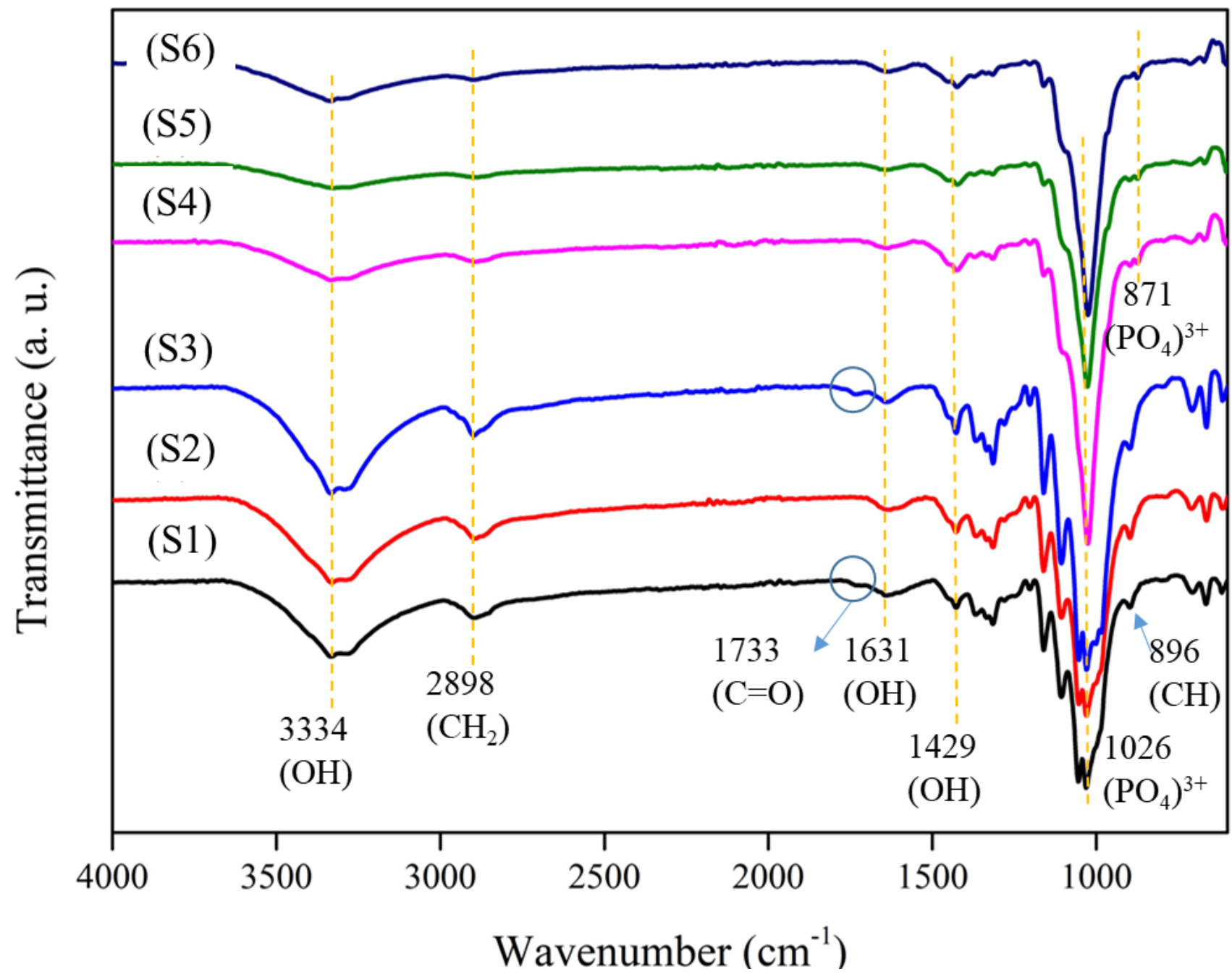

Figure 3

FTIR spectra of (S1) Oxidized-Luffa fibers, (S2) Isolated Cellulose from Luffa, (S3) Oxidized-nanocellulose, (S4) Oxidized-luffa fibers/HAp, (S5) Cellulose/HAp, and (S6) Oxidized-nanocellulose/HAp 


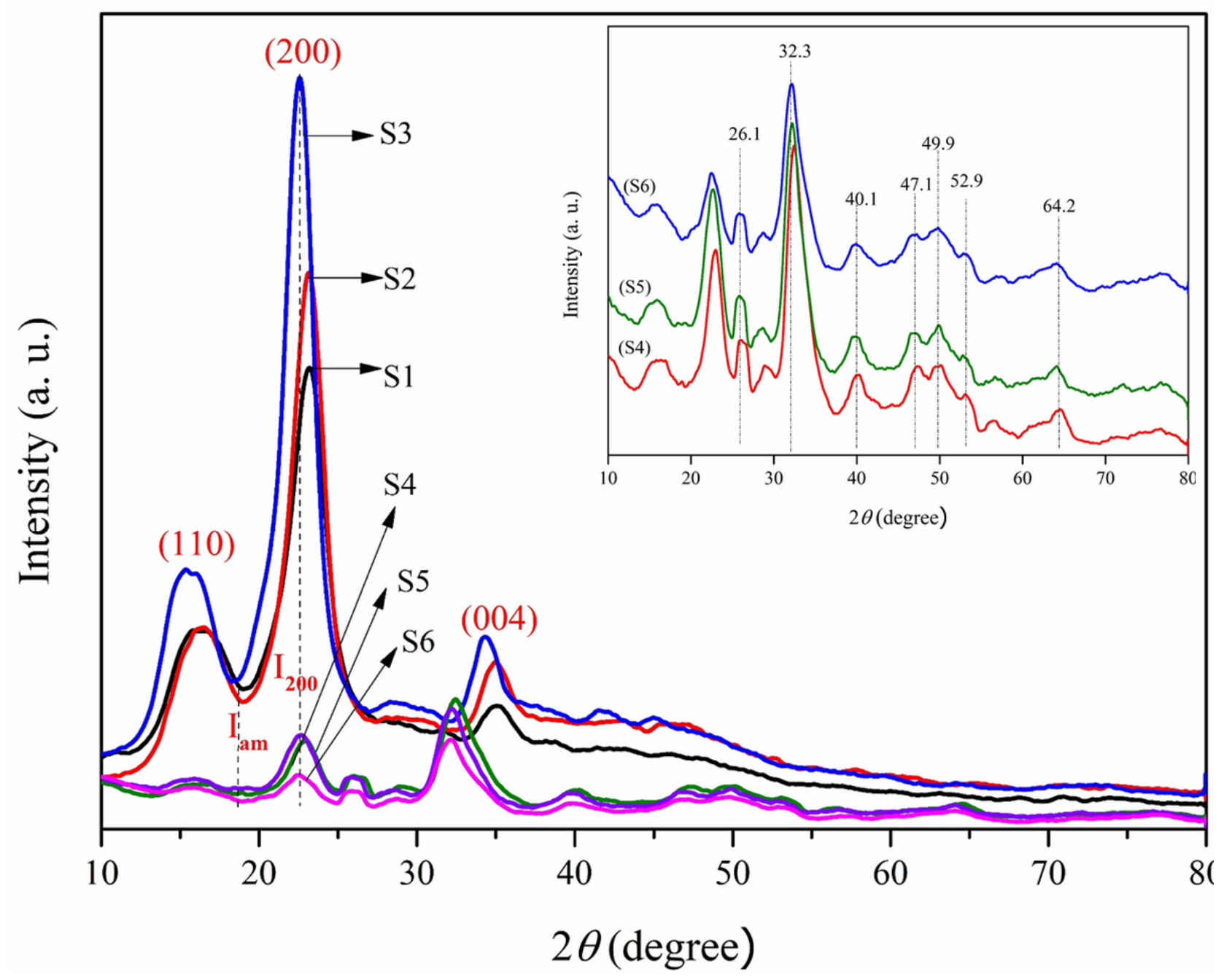

Figure 4

XRD spectra of (S1) Oxidized-Luffa fibers, (S2) Isolated cellulose from luffa, (S3) Oxidized-nanocellulose, (S4) Oxidized-luffa fibers/HAp, (S5) Cellulose/ HAp, and (S6) Oxidized-nanocellulose/HAp
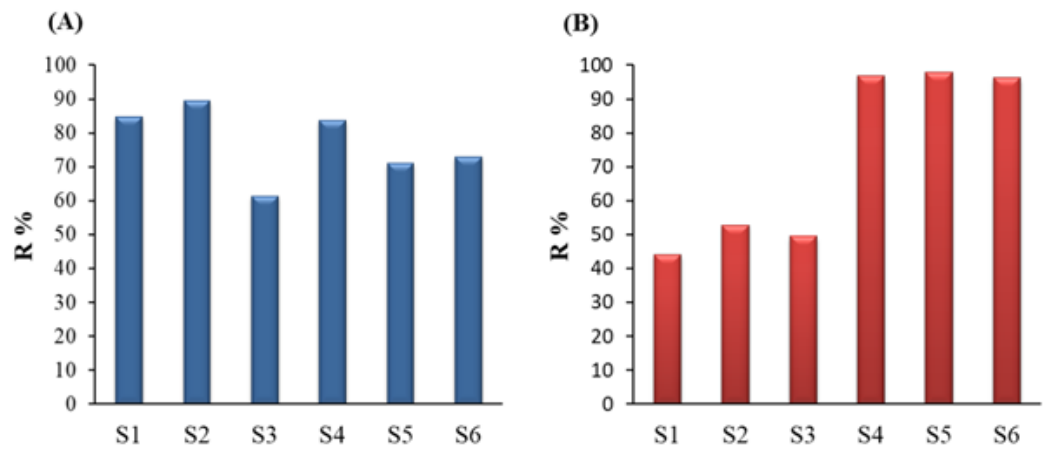

Figure 5

Removal efficiency for $(\mathrm{A})$ methylene blue $(\mathrm{MB})$ and $(\mathrm{B})$ and lead ions $(\mathrm{Pb} 2+)$ by the prepared sorbents for 120 min. Contact time and sorbents dosage 0.4 $\mathrm{g} / 100 \mathrm{~mL}$ at $250 \mathrm{C}$. 
(A)

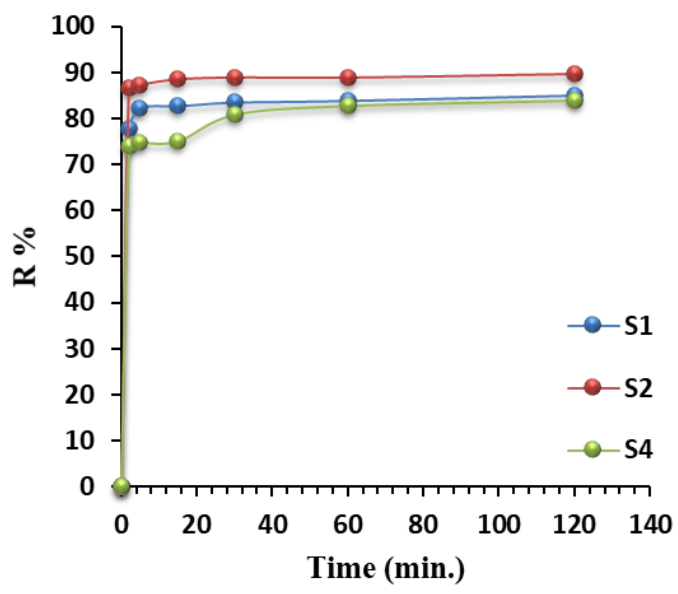

(C)

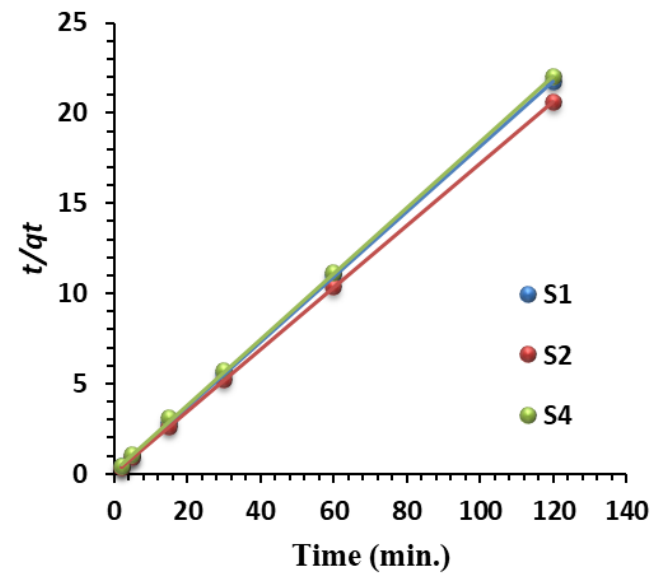

(B)

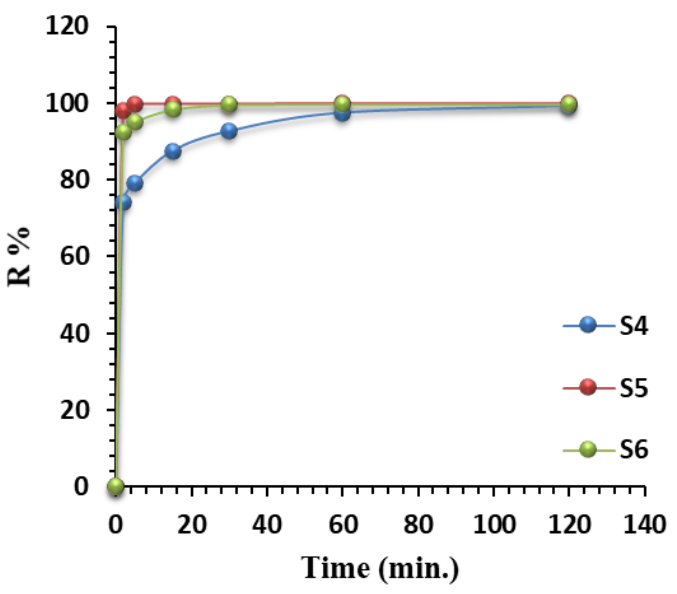

(D)

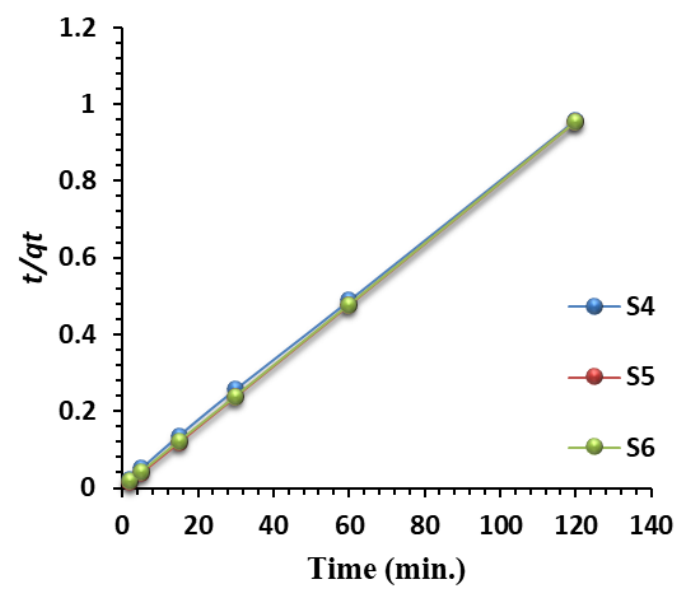

\section{Figure 6}

The removal efficiency of sorbents for (A) methylene blue (25 mg/L), and (B) lead ions ( $500 \mathrm{mg} / \mathrm{L}$ ), Pseudo-second-order adsorption fitting for (C) methylene blue, and (D) lead ions, using $0.4 \mathrm{~g}$ of sorbents as a function of contact time (2-120 min). 
(A)

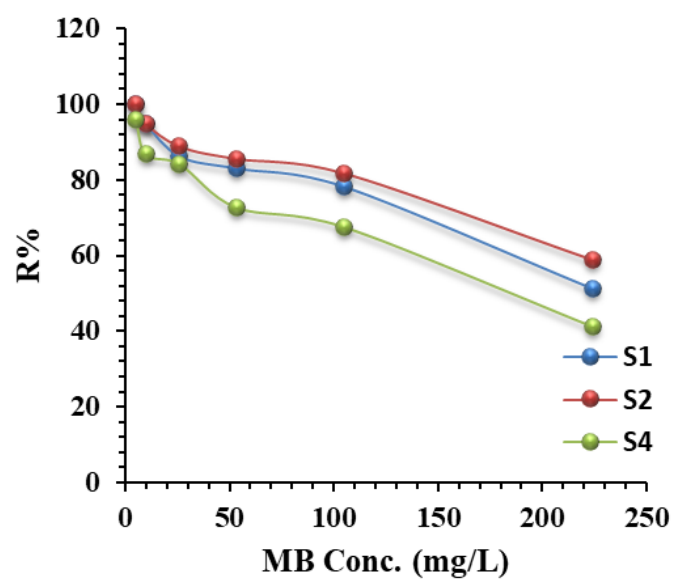

(C)

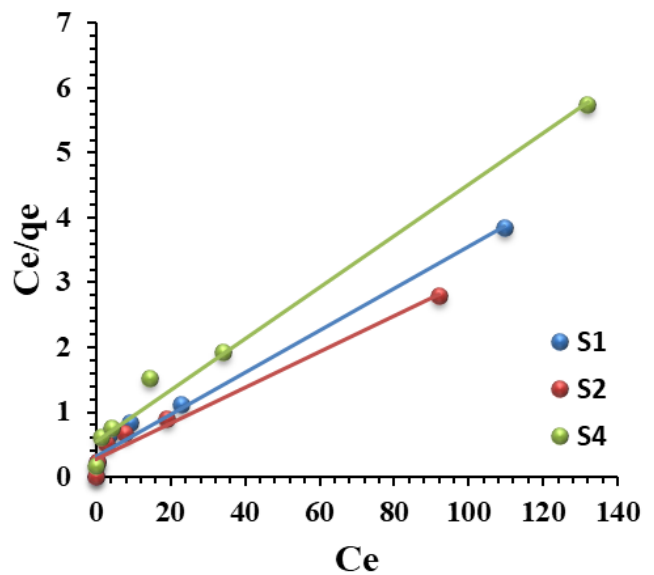

(B)

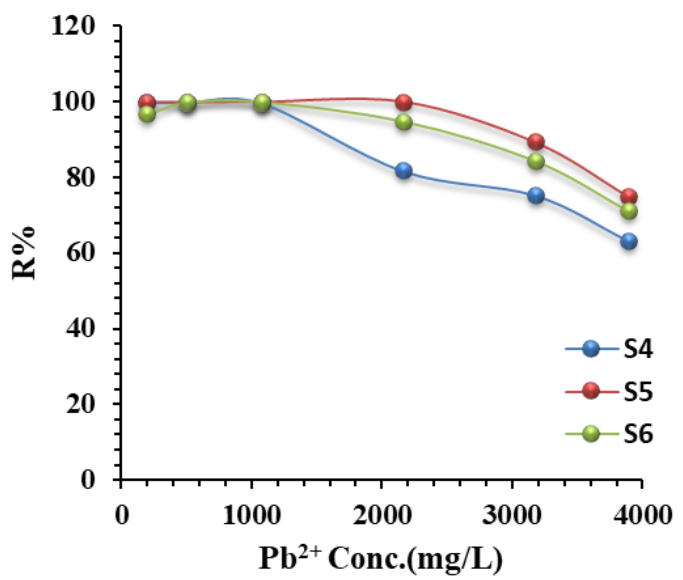

(D)

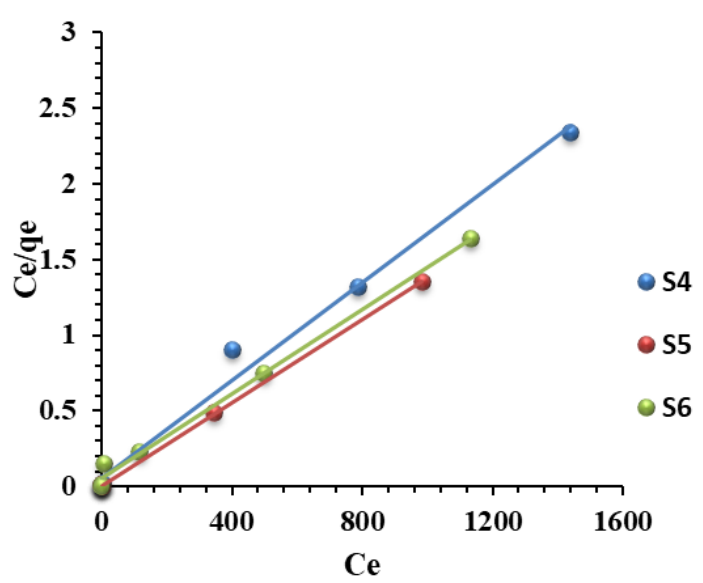

Figure 7

Effect of initial concentrations of (A) MB (5 to $225 \mathrm{mg} / \mathrm{L}$ ) and (B) Pb2+ ions (200 to $4000 \mathrm{mg} / \mathrm{L}$ ) on removal efficiency. Langmuir adsorption isotherm fitting of $\mathrm{MB}(\mathrm{C})$ and $\mathrm{Pb} 2+$ ions (D). (sorbents dose $=0.4 \mathrm{~g}$, contact time $=120 \mathrm{~min}$ ). 